\title{
Renal Ultrasonography in the Evaluation of Acute Kidney Injury in the Emergency Department
}

\author{
Bennidor Raviv*, Shlomo Hanan Israelit \\ Department of Emergency Medicine, Rambam Medical Center, Haifa, Israel
}

*Corresponding author: bennyraviv@gmail.com

Received September 19, 2014; Revised October 20, 2014; Accepted November 06, 2014

\begin{abstract}
Background: Acute kidney injury is common in hospitalized patients, and is associated with high rates of morbidity and mortality. Only in a small part of cases it is secondary to obstructive etiologies. Ultrasonography of the urinary tract is todaya routine part of the evaluation of patients with acute kidney injury, and is debated regardingits value in the evaluation of all patients with acute kidney injury. Methods: A retrospective analysis of data of patients who presented to the emergency department of a tertiary medical center with acute kidney injury and who underwent ultrasound studies of the urinary tract. Aims: to evaluate the effectiveness of ultrasonography as a routine part in the evaluation of acute kidney injury in the emergent setting and to identify factors that may identify patients who will benefit of the study and patients who will not. Results: Substantial obstructive pathology was detected in more than $10 \%$ of the studies performed. The known history of nephrolithiasis and the use of antihypertensive medicines of the ARB/ACE groups and of diuretics were factors shown to have effect on the outcome of the studies performed. Conclusions: Ultrasonography is an important part of the routine evaluation of AKI in the emergency room. Use of certain medicines and history of urinary tract stonesare factors predictive of the findings on imaging studies.
\end{abstract}

Keywords: acute kidney injury, ultrasonography, Emergency department

Cite This Article: Bennidor Raviv, and Shlomo Hanan Israelit, "Renal Ultrasonography in the Evaluation of Acute Kidney Injury in the Emergency Department." American Journal of Clinical Medicine Research, vol. 2, no. 5 (2014): 103-105. doi: 10.12691/ajcmr-2-5-3.

\section{Background}

Acute kidney injury [AKI] is a common finding in hospitalized patients.

The prevalence of $\mathrm{AKI}$ is estimated as $5 \%$ to $18 \%$ in different studies [1,2].

AKI is important, for it carries great influence on the management, clinical course and prognosis of the patient $[3,4]$.

In most cases, AKI is secondary to systemic processes: infection and sepsis, trauma, medicines and toxins, diabetes and hypertension.

Only in a small part of the cases [about 5\%], AKI is secondary to post renal/obstructivecauses [5].

Ultrasound [US] is the initial imaging modality of choice in the evaluation of AKI, for exclusion of hydronephrosis and obstructive disorders [6,7].

There is debate in the literature about the affectivity of US in the evaluation of AKI, for Although it has many advantages [Noninvasive, no use of radiation or contrast media, relatively non expensive], the routine use of US in the evaluation of AKI in the emergency department has many disadvantages: the study is user dependent, time consuming and lengthens patient stay in the emergency department, availability [many institutions do not have available US services 24 hours a day, the demonstration of incidental findings, that need later follow up, more imaging, and even invasive evaluation, and costs [5,8,9].

Although calculating various indices using Doppler ultrasonography is proving as a reliable tool for evaluating obstructive pathologies, it is still not a common practice in the routine, plain ultrasonography evaluation $[8,10,11]$.

The aim of this study is to evaluate the effectiveness of US in the evaluation of AKI in the emergency department, and to identify factors that may help recognizing patients for whom the test is not needed to be routinelydone.

\section{Methods}

\subsection{Study Population}

Included were patients presenting to the emergency department of a tertiary, academic, medical center between 01/01/2013 and 30/06/2013, for whom acute kidney injury was identified, and who underwent US study of the kidneys and urinary tract as part of their evaluation.

Inclusion criteria for patients in the study are:

- 18 years old or older.

- Existence of acute kidney injury, defined as at least one of the following criteria:

1. Rise of at least 50\% in creatinine from base line. 
2. Increase of at least $0.3 \mathrm{mg} \%$ creatinine from baseline [only used in patients with no known base line chronic kidney disease].

- Base line kidney function tests available during the last three months prior to inclusion.

- Full data was available about all the parameters examined in the study.

Exclusion criteria:

- Age under 18 years old.

- No base line recent kidney function tests available.

- Not meeting the definitions of AKI as described above.

- Lack of data about other parameters needed for the study.

\subsection{Definitions and Statistical Analysis}

A retrospective analysis of all patients undergoing renal ultrasonography through the emergency department of a tertiary medical center between 01/01/2013 and 30/06/2013.

Ultrasound examinations were defined as "pathologic" if demonstrating obstructive etiology for AKI, and normal if not.

A row of independent parameters were tested for their influence on the outcome of the ultrasound study [the dependent parameter]:

Age and gender of the patient, Creatinine value, BUN [Blood Urea Nitrogen], BUN/creatinine ratio, use of medicines: diuretics, Angiotensin Converting Enzyme inhibitors [ACE inhibitors], and Angiotensin Receptor Blockers [ARB's], fever on presentation or history, abdominal pain as part of the complaints, history of urolithiasis, and oncologic status of the patientStatistical analysis was performed by using SPSS version 21 (SPSS Inc. Chicago, Illinois).

3. The normality of the quantitative parameters was tested by kolmogorov-smirnov tests. As some of the quantitative parameters were not normally distributed, the Mann-Whitney U tests was used for differences between the two groups (Normal vs. pathological US), otherwise T-tests were used for differences between those groups.

Fisher exact tests were used for differences in the categorical parameters.

Logistic regression model was used to study the clinical and demographic parameters associated with pathological US of the Kidney.

$\mathrm{P}<0.05$ was considered as significant.

\subsection{Aims of the Study}

1. To study the usefulness of ultrasonography in the evaluation of AKI in the setting of an emergency department.

2. To identify factors that will help to stratifying patients into those who will benefit from emergent US, and patients in whom it is less likely to be of use.

\section{Results}

137 patients were identified eligible for inclusion, 77 of them males [56.2\%], and 60 females [43.8\%]. Mean age of the patients was 70 years.
Of the studies performed, 121 were defined as "normal" and 16 as "pathologic" [Table 1].

Table 1. outcomes of studies

\begin{tabular}{|c|c|c|c|}
\hline \multicolumn{2}{|c|}{} & Frequency & Percent \\
\hline \multirow{3}{*}{ Valid } & normal us & 121 & 88.3 \\
\cline { 2 - 4 } & pathologic & 16 & 11.7 \\
\cline { 2 - 4 } & Total & 137 & 100.0 \\
\hline
\end{tabular}

The influence of each of the independent parameters on the result of the US was evaluated [Table 2].

Table 2. Influence of independent parameters on ultrasound results

\begin{tabular}{|c|c|c|c|}
\hline & $\begin{array}{l}\text { US-normal } \\
\mathrm{N}=121\end{array}$ & $\begin{array}{c}\text { US-pathology } \\
\mathrm{N}=16\end{array}$ & $\mathrm{p}$-value \\
\hline Gender (male) (\#) & $65(54 \%)$ & $12(75 \%)$ & $\mathrm{P}=0.18$ \\
\hline Age (mean \pm STD) $\left(^{*}\right)$ & $70.15 \pm 14.77$ & $69.18 \pm 14.62$ & $\mathrm{P}=0.81$ \\
\hline $\begin{array}{l}\text { Creatinine(mean } \pm \text { STD, } \\
\text { median) }(* *)\end{array}$ & $\begin{array}{l}3.88 \pm 2.84 \\
(3.21)\end{array}$ & $\begin{array}{l}4.30 \pm 4.49 \\
(2.33)\end{array}$ & $\mathrm{P}=0.36$ \\
\hline $\begin{array}{l}\text { BUN (mean } \pm \text { STD, } \\
\text { median) }(* *)\end{array}$ & $\begin{array}{c}65.7 \pm 41.24 \\
(59)\end{array}$ & $\begin{array}{c}62.3 \pm 48.37 \\
(40.5)\end{array}$ & $\mathrm{P}=0.51$ \\
\hline $\begin{array}{l}\text { BUN/ Creatinine Ratio } \\
(* *)\end{array}$ & $18.36 \pm 8.43$ & $17.22 \pm 6.01$ & $\mathrm{P}=0.92$ \\
\hline Kidney stone (\#) & $4(3.3 \%)$ & $3(18.8)$ & $\mathrm{P}=0.035$ \\
\hline ACE/ARB medication(\#) & $51(42.5 \%)$ & $1(6.7 \%)$ & $\mathrm{P}=0.009$ \\
\hline Diuretics medication(\#) & $49(40.5 \%)$ & $1(6.7 \%)$ & $\mathrm{P}=0.01$ \\
\hline Fever(\#) & $22(18.2 \%)$ & $1(6.3 \%)$ & $\mathrm{P}=0.31$ \\
\hline Pain(\#) & $22(18.2 \%)$ & $5(31.3 \%)$ & $\mathrm{P}=0.31$ \\
\hline Oncology(\#) & $25(20.7 \%)$ & $5(31.3 \%)$ & $\mathrm{P}=0.34$ \\
\hline
\end{tabular}

Known history of urinary tractstones, and the use of diuretics and/or ACE or ARB was found to be significant on the study's outcome.

12 of the 16 pathologic studies [75\%] were in males, yet there was no statistical significance when compared to women $[\mathrm{p}=0.18]$.

\section{Discussion}

The prevalence of AKI reaches up to $35 \%$ in hospitalized patients, and it is Associated withmajor morbidities and mortality [1,2,3,4].

Ultrasonography is recommended by most guidelines and authors as part of the routine evaluation of AKI.

Some authors argue for more selective use of ultrasonography in the evaluation of AKI, mentioning that the vast majority of cases [90-95\%] are due to pre renal causes or acute tubular necrosis, and that even when found, hydroneprosis is many times secondary to other problems than obstructive reasons - problems that require medical and not surgical treatment, or conditions "mimicking" hydronephrosis, such as high urinary flowsituations $[5,9,10]$.

Cutting down numbers of ultrasound studiesmay have advantages:

- Cutting down costs

- Shortening delays in the evaluation of patients in the emergency department

- Lowering number of incidental findings requiringmore evaluation and follow up, sometimes even invasive tests.

One study [5] evaluating the possibility of reducing number of ultrasonography studies performed, calculated the cost of finding 1 case of hydronephrosis requiring intervention to be over 44000 US dollars by performing routine ultrasonography for all cases of AKI without screening of for those in high risk for obstruction! 
Various factors were demonstrated in previous studies as predictive of increased effectiveness of US in identifying obstructive disorders: malignancy, older age, and known intra abdominal and urinary tract anomalies $[5,8]$.

In our study we found that US is a valuable part of the emergent evaluation of AKI, as $11.7 \%$ of the tests performed were significant for a substantial disorder: to note that in order to increase the effectiveness of the study we only defined positive results as moderate hydroneprosis at least, and excluded mild disturbances, that are likely to be reactive to other pathologic processes, and not true obstructive problems.

The vast majority of factors evaluated for their influence on the outcome of the studies performed were found to have no influence on the outcome.

History of urinary tract calculi was found to be predictive of positive US result for substantial hydroneprosis, yet $10 \%$ of the patients with no known history of urinary tract calculi also had significant findings on ultrasonography, making the study relevant for them too.

The confidence interval for the influence of presence of urinary calculi in the history on the study result was wide, presumably due to the small sample size in the study.

The use of medicines with potential for causing renal failure was demonstrated to substantially decrease the risk for obstructive findings on US, with only 1 out of 52 patients using ACE or ARB class [1.9\%], and 1 out of 50 patients using diuretics [2\%] were found to have positive US results.

We evaluated the potential effects of these medicines because their use is common, they have be shown in previous studies [12,13] to worsen AKI, probably by interrupting the adaptation of the kidneys to potential hazards, so our hypothesis was that their use is likely to decrease the likelihood of obstructive disturbances as causes of AKI. the relation between BUN and Creatinine on the outcome of the US was also evaluated: this ratio, though not sensitive, is a known marker of pre renal injury when is higher than 20 [14,15].

We estimated that an elevated ratio will be indicative for a negative US result, but no difference was found between positive and negative US results.

Other variants evaluated by us, which were found to be predictive of the US findings in previous studies, were not found to be significant in this study: age, oncologic background of the patient - the fact that oncologic background of the patient did not have significance on the outcome in our study is probably due to the small scale of the study, and that all types of malignancies were included as a whole, for it is reasonable that some malignancies are more prone to cause urinary tract obstruction than others [gynecologic and gastrointestinal malignancies for examples].

\section{Conclusions}

Renal ultrasonography is an important part in the evaluation of patients presenting to the emergency department with acute kidney injury, as more than $10 \%$ of the patients had significant findings on the study.
Most parameters evaluated by us were not found to be predictive of the study's results.

The known history of nephrolithiasis and the use of diuretics and ARB/ACE medicines were parameters that were found by us to influence the outcome of the study.

There are no studies known to us, to this date, which evaluate the utility of US in the evaluation of AKI in the emergency department setting, and only few studies that evaluate its value in hospitalized patients as a whole for the evaluation of AKI.

The main limitations of our study are it's being small and retrospective.

Another limitation is the fact that Doppler evaluation was not performed during the studies, but this is a common problem in most medical centers [8].

There is need to conduct larger scale, prospective, randomized trials in order to determine the exact role of ultrasonography in the evaluation of AKI in the emergent setting.

\section{References}

[1] Walker SS, Liu KD, Chertow GM et al. Diagnosis, epidemiology and outcomes of acute kidney injury. Clin J Am Soc Nephrol. 2008; 3 (3): 844-861.

[2] Liangos O, Wald R, O'Bell JW, Price L, Pereira BJ, Jaber BL. Epidemiology and outcomes of acute renal failure in hospitalized patients: a national survey. Clin J Am Soc Nephrol Jan. 2006; 14 (1): 43-51.

[3] Chertow GM, Burdick E, Honour M, Bonventre JV, Bates DW. Acute kidney injury, mortality, length of stay, and costs in hospitalized patients. J Am SocNephrol Nov. 2005; 14 (11): 33653370 .

[4] Challiner R, Ritchie JP, Fullwood C, Loughnan P, Hutchinson AJ. Incidence and consequence of acute kidney injury in unselected emergency admissions to a large acute UK hospital trust. BMC Nephrol. 2014 May 29; 15: 84.

[5] Licurse A, Kim MC, Dziura J, Forman HP, Formica RN, Makarov DV, Parikh CR, Gross CP. Renal ultrasonography in the evaluation of acute kidney injury: developing a risk stratification framework. Arch Intern Med. 2010 Nov 22; 170 (21): 1900-7.

[6] Edelstein CSchrier R Pathophysiology of ischemic acute renal failure. Schrier RW Diseases of the kidney and urinary tract. $7^{\text {th }}$ ed. Philadelphia, PA Lippincott Williams and Wilkins 2001:10411070 .

[7] Bellomo R, Kellum JA, Ronco C. Acute kidney injury. Lancet. 2012; 14 (9843): 756-766.

[8] Podoll A, Walther C, Finkel K. Clinical utility of gray scale renal ultrasound in acute kidney injury. BMC Nephrol. 2013 Sep 8; 14: 188.

[9] Gottlieb RH, Weinberg EP, Rubens DJ, Monk RD, Grossman EB. Renal sonography: can it be used more selectively in the setting of an elevated serum Creatinine level? Am J Kidney Dis Mar. 1997; 14 (3): 362-367.

[10] Ritchie WW, Vick CW, Glocheski SK, Cook DE. Evaluation of azotemic patients: diagnostic yield of initial US examination. Radiology Apr. 1988; 14 (1): 245-247.

[11] Le Dorze M, Bougle A, Deruddre S, Duranteau J. Renal Doppler ultrasound: a new tool to assess renal perfusion in critical illness. Shock Apr. 2012; 14 (4):360-365.

[12] Bentley ML, Corwin HL, Dasta J. Drug-induced acute kidney injury in the critically ill adult: recognition and prevention strategies. Crit Care Med. 2010; 38 (6 Suppl): S169-S174.

[13] Pannu N, Nadim MK. An overview of drug-induced acute kidney injury. Crit Care Med. 2008; 36 (4 Suppl): S216-S223.

[14] Cecil RL, Goldman L, Ausiello DA. Cecil Medicine. Philadelphia, PA: Saunders Elsevier; 2008

[15] Brisco MA, Coca SG, Chen J, Owens AT, McCauley BD, Kimmel SE, Testani JM. Blood urea nitrogen/ Creatinine ratio identifies a high risk but potentially reversible form of renal dysfunction in patients with decompensated heart failure. Circ heart Fail. 2013 Mar; 6 (2): 233-9. 2013 Jan 16. 